\title{
Three-Dimensional Finite Element Analysis to Evaluate Stress Distribution in Tooth and Implant- Supported Fixed Partial Denture-An In Vitro Study
}

\author{
Himani Jain ${ }^{1}$ Tarun Kalra ${ }^{1}$ Manjit Kumar ${ }^{1} \quad$ Ajay Bansal $^{1}$ Deepti Jain ${ }^{2}$ \\ 1Department of Prosthodontics, Bhojia Dental College and Hospital, \\ Baddi, Solan, Himachal Pradesh, India \\ 2Department of Periodontics, Bhojia Dental College and Hospital, \\ Baddi, Solan, Himachal Pradesh, India

\begin{abstract}
Address for correspondence Manjit Kumar, MDS, Department of Prosthodontics, Bhojia Dental College, Baddi, Solan, Himachal Pradesh 173205, India (e-mail: manjitkiran@yahoo.co.in).
\end{abstract}

Dent J Adv Stud:2020;8:84-91

\begin{abstract}
Keywords

- implant

- finite element analysis

- stress distribution
\end{abstract}

Introduction This study was undertaken to assess the influence of different superstructure materials, when subjected to occlusal loading, on the pattern of stress distribution in tooth-supported, implant-supported, and tooth implant-supported fixed partial prostheses, using the finite element analysis with a comparative viewpoint.

Materials and Methods The geometric models of implant and mandibular bone were generated. Three models were created in accordance with the need of the study. The first model was given a tooth-supported fixed partial prosthesis. The second model was given tooth implant-supported fixed partial prosthesis, and the third model was given implant-supported fixed partial prosthesis. Forces of $100 \mathrm{~N}$ and $50 \mathrm{~N}$ were applied axially and buccolingually, respectively.

Results The present study compared the stresses arising in the natural tooth, implant, and the whole prostheses under simulated axial and buccolingual loading of three types of fixed partial dentures, namely, tooth-supported, tooth implant-supported, and implant-supported fixed partial dental prostheses using three different types of materials.

Conclusion The pattern of stress distribution did not appear to be significantly affected by the type of prosthesis materials in all models. The maximum stress concentrations were found in the alveolar bone around the neck of the teeth and implants.

\section{Introduction}

In modern dentistry, restoration of missing teeth is a challenging aspect. Nowadays, the aim of dentistry is to restore the patient's oral condition to normal comfort, function, contours, speech, esthetics, and health, despite disease, atrophy, or injury to the stomatognathic system. ${ }^{1}$

Conventional methods of restoration include removable complete dentures, removable partial dentures or fixed partial dentures (FPDs). Each method has its own indications and its share of advantages and disadvantages.

Fixed prostheses appear to be more natural and more convenient, but they involve preparation of abutment teeth which could lead to a different set of problems such as secondary decay or irreversible pulpitis. The use of osseointegrated implants to support prostheses in partially edentulous patients is a relatively new treatment modality. ${ }^{2}$

An osseointegrated implant is rigidly fixed to bone and can move only $10 \mu \mathrm{m}$ in the apical direction, whereas teeth with healthy periodontal ligaments can move 25 to $100 \mu \mathrm{m}$. This movement disparity is believed to cause motion of the implant-tooth superstructure when the splinted system is loaded by occlusal force. There are also various benefits of tooth used in conjunction with implant such as occlusal support and relief to a portion of the total load on the natural teeth, maintenance of proprioception, reduction of the 
number of implant abutments, and assistance in the splinting of natural dentition. ${ }^{3}$

Various clinical studies have documented high rates of success and survival along with variable rates of implant failures. The most frequently cited reasons for implant failure are poor oral hygiene and biomechanical factors. ${ }^{4}$

As we know that biomechanical factors play an important role in the long-term survival of oral implants, the selection of implant position, prosthesis design and superstructure material are critical for the longevity and stability of the implant prosthesis. A meticulous treatment plan drawn, keeping these factors in mind, can help enhance the success of implant prostheses. The discipline of biomedical engineering, which applies engineering principles to living systems, has unfolded a new era in diagnosis, treatment planning and rehabilitation in patient care. One aspect of this field is biomechanics which is concerned with the response of biological tissues to applied loads. Biomechanics uses the tools and methods of applied engineering mechanics to search for structure-function relationships in living systems. Advancement in prosthetic implant and instrumentation design has been realized because of mechanical design optimization theory and practice.

The finite element modeling technique is one such tool that enables us to simulate the existing oral conditions and analyze the interplay of the prosthetic and biological systems and its consequences with reasonable accuracy. ${ }^{5,6}$

This research article was an attempt to assess the influence of different superstructure materials, when subjected to occlusal loading, on the pattern of stress distribution in tooth-supported, implant-supported, and tooth implant-supported FPDs using the finite element analysis with a comparative viewpoint.

\section{Materials and Methods}

The present study was conducted in the Department of Prosthodontics and Crown \& Bridge, Bhojia Dental College and Hospital, Baddi, Himachal Pradesh, using the finite element method (FEM), with technical assistance from a mechanical engineer at CADD CENTRE, Chandigarh. It was approved by the Institutional Ethical Committee.

\section{Computational Facilities Used for the Study}

- Models were reconstructed using the scanned image obtained by Reverse Engineering Programme(I-deas Siemens, Germany).

- Surface data of the bone model was generated using Solid Works software (Dassault System SolidWorks Corporation, Waltham, United States).

- Stress analysis was performed using ANSYS 18.1 software (ANSYS 18.1, Inc, United States).

\section{Methodology}

The geometric models of implant and mandibular bone were generated. A graphic preprocessing software Ansys version 18.1 was used for creating geometric configuration of the mandibular model, nodes and elements for conducting a finite element analysis. Then, the data was imported into Solid Works software to create three dimensional (3D) models of mandible along with tooth, implant, periodontal membrane, surrounding osseous tissue, and prosthesis as a collection of geometric structural elements interconnected at a finite number of nodal points. Three models were created in accordance with the need of the study. The first model was having a missing mandibular first molar. The second model was with all the molars missing, and in the third model, the second premolar was also missing along with all the molars. The first model was given a tooth-supported fixed partial prosthesis using the second premolar and second molar as

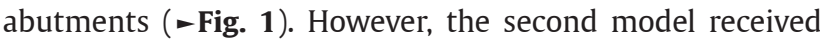
a single root-form implant in the second molar region and was given tooth implant-supported fixed partial prosthesis ( -Fig. 2); the third model received two such implants, one in the second premolar region and another in the second molar region, and was given implant-supported fixed partial prosthesis ( - Fig. 3 ).

The created models were then transferred to ANSYS software. Then, meshing was performed. The finite element model consisted of nodes and elements ( - Table $\mathbf{1}$ ). The material properties of implant, tooth, bone and material of

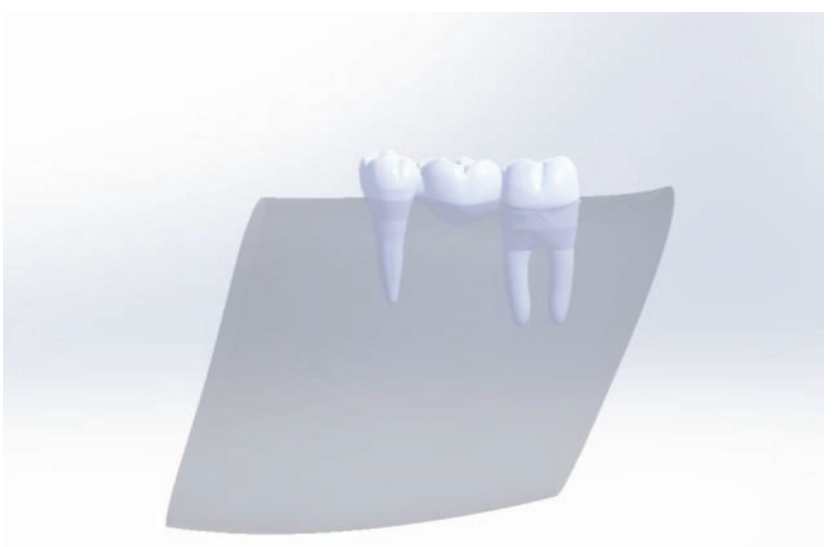

Fig. 1 Tooth-supported fixed partial denture.

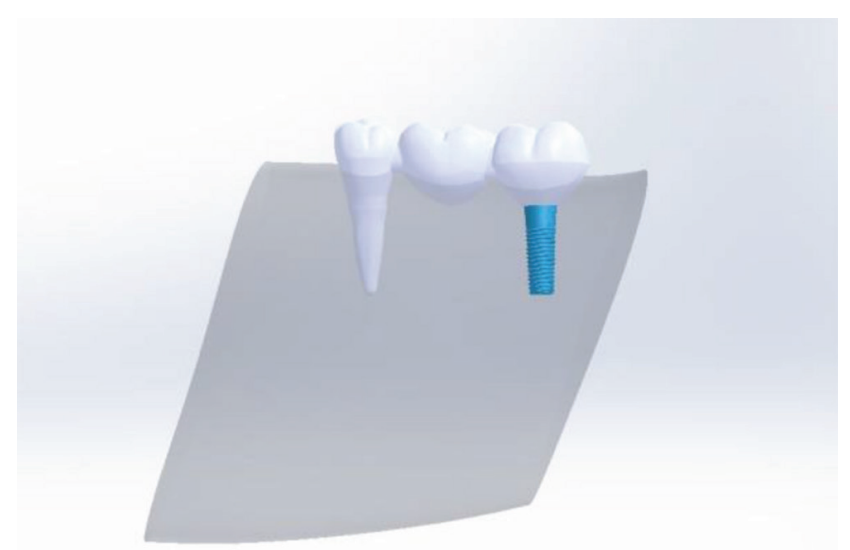

Fig. 2 Tooth implant-supported fixed partial denture. 
prosthesis were then entered in the preprocessing stage. ${ }^{7}$ The components of the model were individually modeled with different physical properties ( $\mathbf{- T a b l e ~} 2$ ), and the components were assembled to create a $3 \mathrm{D}$ finite element model. The entire assembly was then exported for analysis with ANSYS Workbench (ANSYS 18.1, Inc, USA) through a bidirectional understandable translated system called Initial Graphics Exchange Specification (IGES). An assessment of the stress on the bone and implant interface or bone and tooth interface was performed by using Von Mises stress at bone. A color scale with stress values was used to quantitatively evaluate

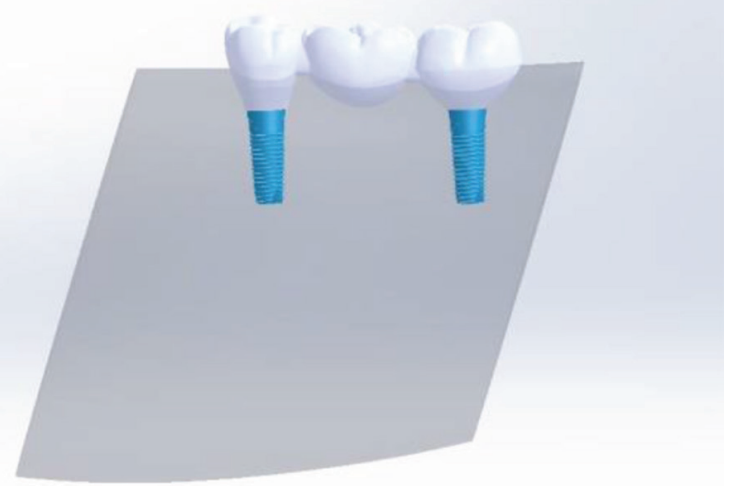

Fig. 3 Implant-supported fixed partial denture.

Table 1 Number of elements and nodes in the finite element models of interest

\begin{tabular}{|l|l|l|}
\hline Type of models & Elements & Nodes \\
\hline Tooth-supported FPDs & 94665 & 146491 \\
\hline Tooth implant-supported FPDs & 141253 & 209361 \\
\hline Implant-supported FPDs & 158835 & 239438 \\
\hline
\end{tabular}

Abbreviation: FPD, fixed partial denture.

Table 2 Material properties of the structures and materials of interest

\begin{tabular}{|l|l|l|}
\hline Materials & $\begin{array}{l}\text { Young's modulus } \\
\text { (MPa) }\end{array}$ & Poisson's ratio \\
\hline Titanium & 110,000 & 0.35 \\
\hline Enamel & 84100 & 0.20 \\
\hline Pulp & 2 & 0.45 \\
\hline Dentin & 18,600 & 0.31 \\
\hline $\begin{array}{l}\text { Periodontal } \\
\text { ligament }\end{array}$ & 69 & 0.45 \\
\hline Cortical bone & 15,000 & 0.30 \\
\hline Cancellous bone & 1500 & 0.30 \\
\hline Ni-Cr alloy & 170,000 & 0.26 \\
\hline Porcelain & 70,000 & 0.19 \\
\hline Zirconia & 210000 & 0.27 \\
\hline
\end{tabular}

the stress distribution in the bone and implant interface or bone and tooth interface. The scale for stress runs from $0 \mathrm{MPa}$ (blue) to the highest stress and strain values (red).

\section{Constraints and Loads}

The models were constrained in all directions at the nodes on the distal end surface of the bone segment. Forces of $100 \mathrm{~N}$ and $50 \mathrm{~N}$ were applied axially and buccolingually, respectively, to the center of the occlusal surface of each retainer and pontic. The maximum Von Mises equivalent stresses were calculated. The following models were analyzed for stress distribution pattern after the simulated loading:

For tooth-supported fixed partial prostheses,

Model 1. 3-unit FPD with $\mathrm{Ni}-\mathrm{Cr}$ alloy (-Fig. 4)

Model 2. 3-unit FPD with porcelain fused to metal (-Fig. 5) Model 3. 3-unit FPD with zirconia (-Fig. 6)
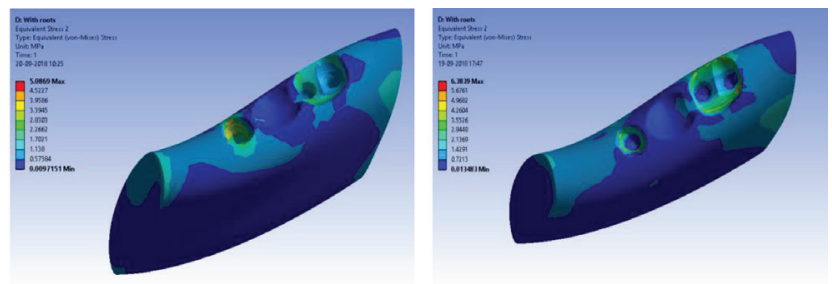

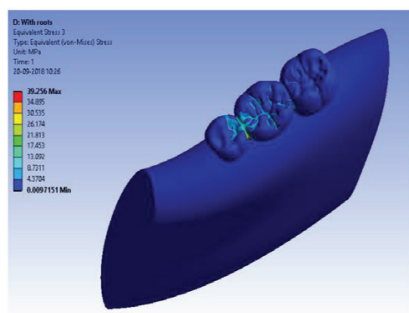

Axial Force

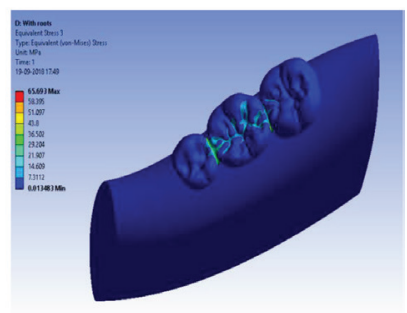

Buccolingual Force
Fig. 4 Stress distribution around bone and tooth in tooth-supported fixed dental prosthesis with prosthesis material $\mathrm{Ni}-\mathrm{Cr}$ alloy.
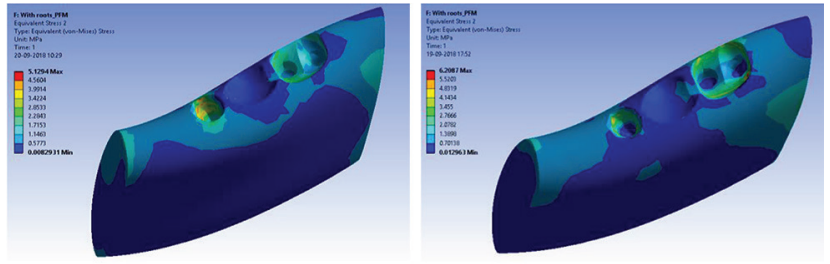

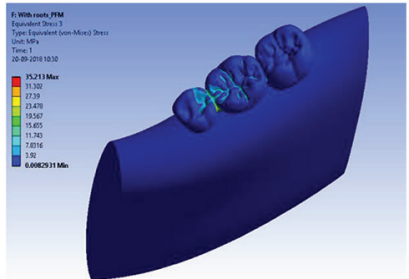

Axial Force

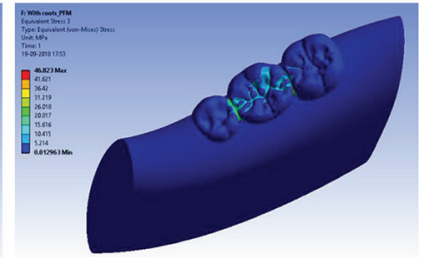

Buccolingual Force
Fig. 5 Stress distribution around tooth and bone in tooth-supported fixed dental prosthesis with prosthesis material porcelain fused to metal. 
For tooth implant-supported fixed partial prostheses,

Model 4. 3-unit FPD with Ni-Cr alloy (- Fig. 7)

Model 5. 3-unit FPD with porcelain fused to metal ( - Fig. 8) Model 6. 3-unit FPD with zirconia (- Fig. 9)

For implant-supported fixed partial prostheses,

Model 7. 3-unit FPD with $\mathrm{Ni}-\mathrm{Cr}$ alloy (-Fig. 10)

Model 8. 3-unit FPD with porcelain fused to metal ( - Fig. 11) Model 9. 3-unit FPD with zirconia (-Fig. 12)
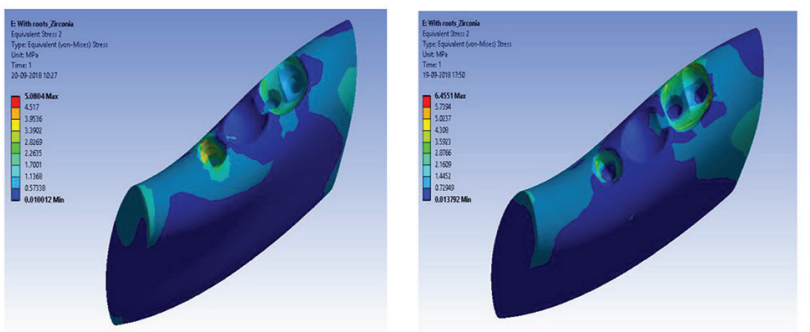

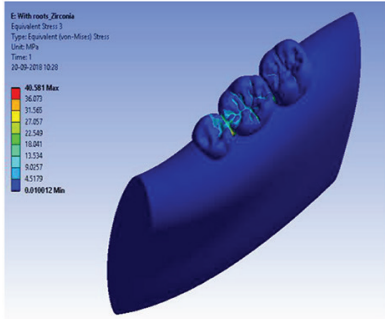

Axial Force

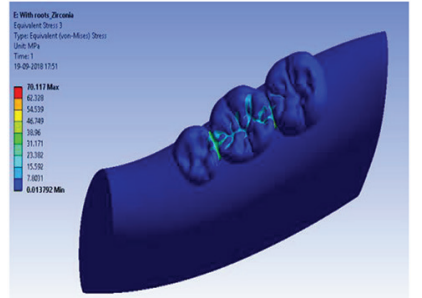

Buccolingual Force
Fig. 6 Stress distribution around tooth and bone in tooth-supported fixed dental prosthesis with prosthesis material zirconia.
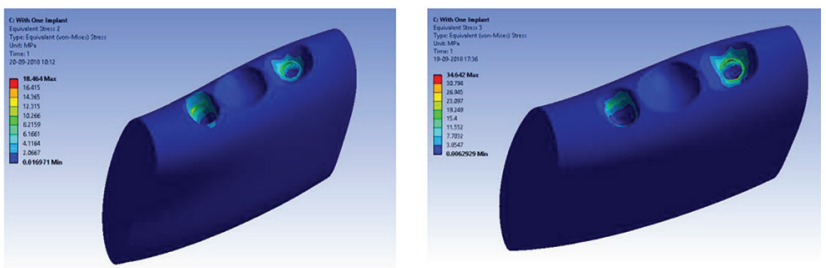

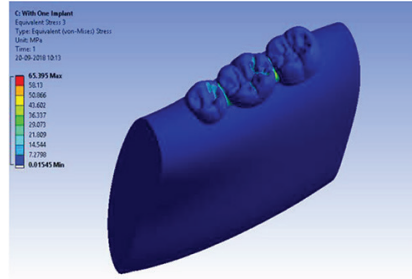

Axial Force

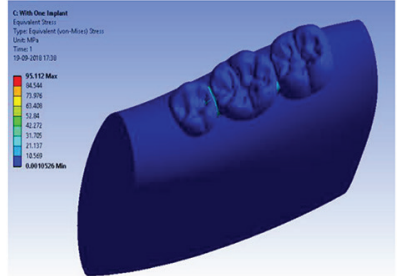

Buccolingual Force
Fig. 7 Stress distribution around bone and tooth and bone and implant in tooth implant supported fixed dental prosthesis with prosthesis material $\mathrm{Ni}-\mathrm{Cr}$ alloy.

\section{Results}

The present study compared the stresses arising in the natural tooth, implant, and the whole prostheses under simulated axial and buccolingual loading of three types of FPDs, namely, tooth-supported, tooth implant-supported and implant-supported fixed partial dental prosthesis using three different types of materials.

In tooth-supported FPD, stresses were almost similar in all the three prosthesis materials used on axial loading. The lowest Von Mises stress was seen in the zirconia model, that
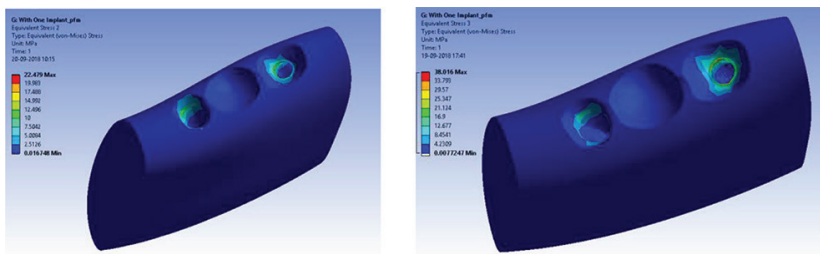

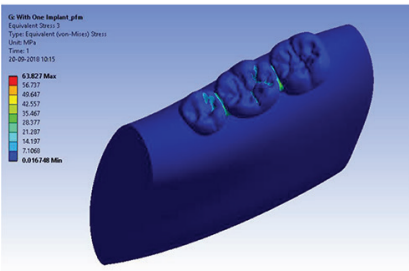

Axial Force

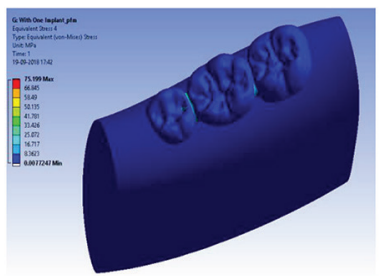

Buccolingual Force
Fig. 8 Stress distribution around tooth and bone and tooth and implant in tooth implant-supported fixed dental prosthesis with prosthesis material porcelain fused to metal.
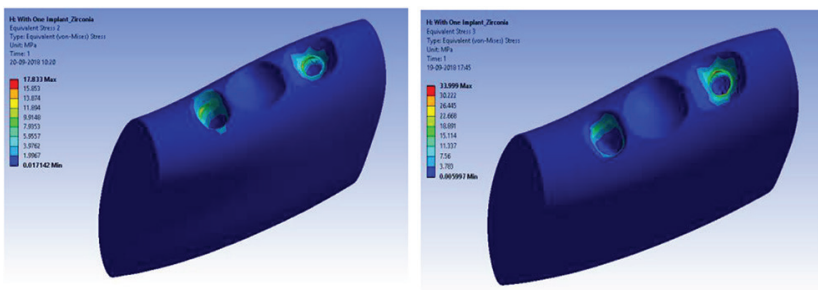

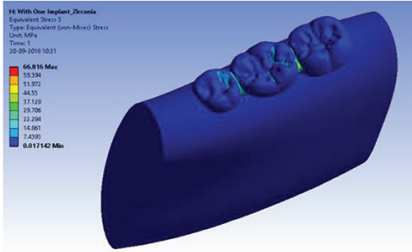

Axial Force

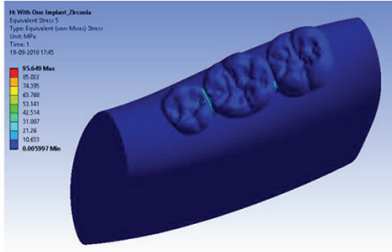

Buccolingual Force
Fig. 9 Stress distribution around tooth and bone and implant and bone in tooth implant-supported fixed dental prosthesis with prosthesis material zirconia. 

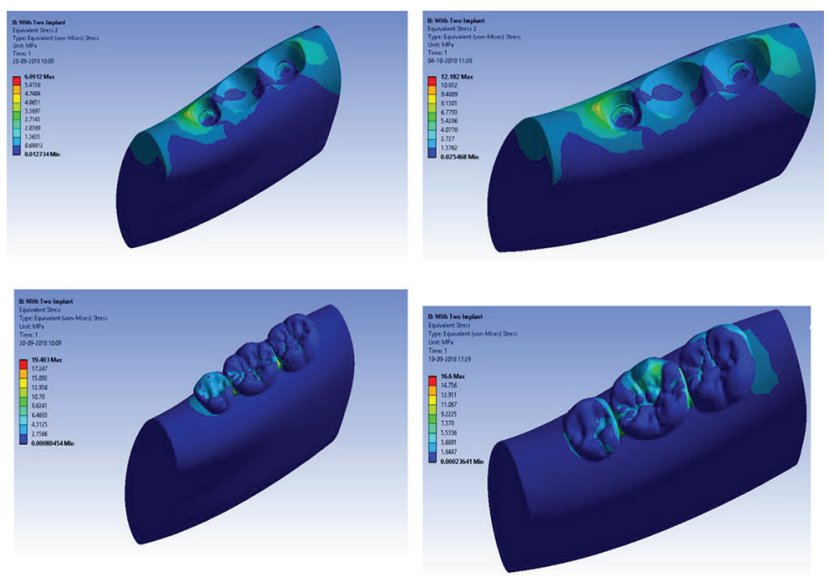

Axial Force

Buccolingual Force

Fig. 10 Stress distribution around implant and bone in implant-supported fixed dental prosthesis with prosthesis material $\mathrm{Ni}-\mathrm{Cr}$ alloy.
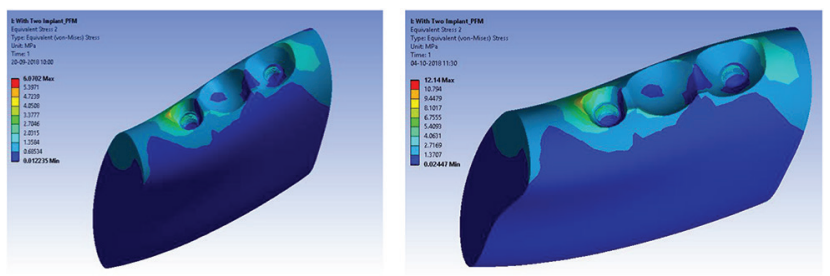

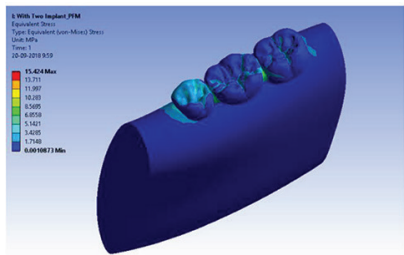

Axial Force

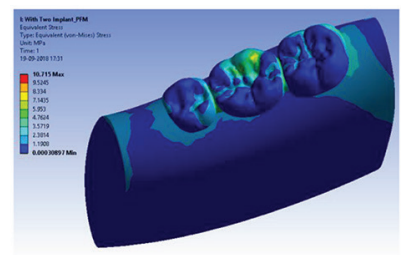

Buccolingual Force
Fig. 11 Stress distribution around implant and bone in implant-supported fixed dental prosthesis with prosthesis material porcelain fused to metal.
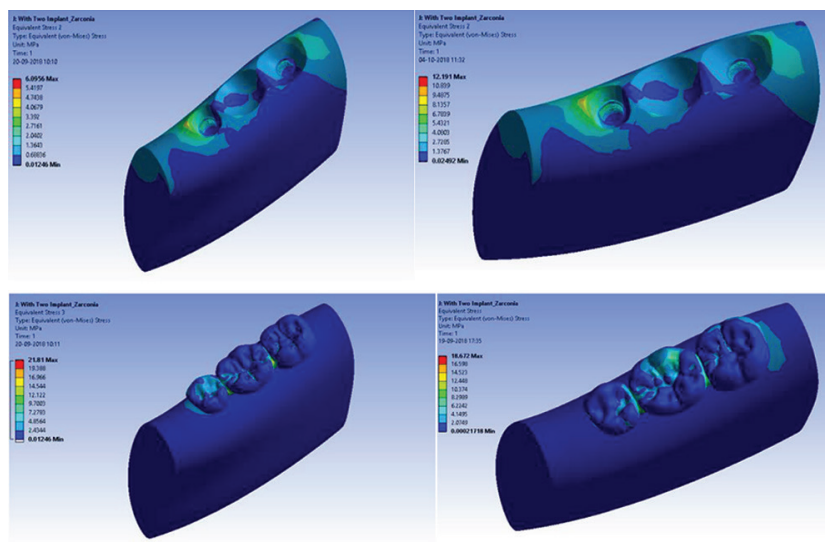

\section{Axial Force}

Buccolingual Force

Fig. 12 Stress distribution around implant and bone in implant-supported fixed dental prosthesis with prosthesis material zirconia. is, $3.62 \mathrm{MPa}$ in the second premolar region and 1.41 MPa in the second molar region, whereas the $\mathrm{Ni}-\mathrm{Cr}$ model showed the highest Von Mises stress, that is, $3.67 \mathrm{MPa}$ in second the premolar region and $2.53 \mathrm{MPa}$ in the second molar region, as shown in - Table 3 and - Fig. 13.

On buccolingual loading, stresses remain almost similar in spite of the material used for the prosthesis. The lowest Von Mises stress was seen in the zirconia model, that is, $1.80 \mathrm{MPa}$ in the second premolar region and 4.30 MPa in the second molar region, whereas the $\mathrm{Ni}-\mathrm{Cr}$ model showed the highest Von Mises stress, that is, $2.48 \mathrm{MPa}$ in the second premolar region and $4.96 \mathrm{MPa}$ in the second molar region, as shown in - Table 4 and -Fig. 14.

In the tooth implant-supported FPD on axial loading, the stress concentration was more on the mesial side of both the root and the implant. The alveolar bone around the implant in the molar region was showing a significantly greater stress concentration than that around the premolar root. Von Mises stresses were much higher in case of the porcelain fused to metal model, that is, $16.23 \mathrm{MPa}$ in the second premolar region and 19.98 MPa in the second molar region and were least for zirconia, that is, $12.88 \mathrm{MPa}$ in the second premolar region and $16.84 \mathrm{MPa}$ in the second molar region, as shown in - Table 5 and - Fig. 15.

On buccolingual loading, Von Mises stresses were much higher in case of the porcelain fused to metal model, that is, 19.01 MPa in the second premolar region and 25.34 MPa in the second molar region and were least for zirconia, that is, 13.22 MPa in the second premolar region and 22.66 MPa in the second molar region, as shown in - Table 6 and - Fig. 16 .

Table 3 The von Mises stresses (Mpa) in the alveolar bone on axial loading of the tooth-supported FPD.

\begin{tabular}{|l|l|l|l|l|}
\hline \multicolumn{2}{|c|}{ Prosthesis material } & $\begin{array}{l}\text { Ni-Cr } \\
\text { alloy }\end{array}$ & $\begin{array}{l}\text { Porcelain } \\
\text { fused to } \\
\text { metal }\end{array}$ & Zirconia \\
\hline $\begin{array}{l}\text { Von Mises } \\
\text { stress }\end{array}$ & Second premolar & 3.67 & 3.70 & 3.62 \\
\cline { 2 - 5 } & Second molar & 2.53 & 1.95 & 1.41 \\
\hline
\end{tabular}

Abbreviation: FPD, fixed partial denture.

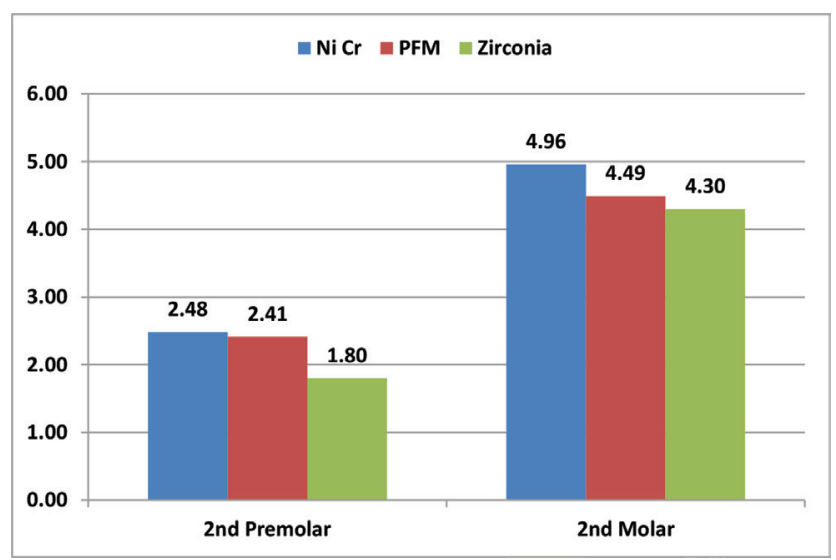

Fig. 13 The Von Mises stresses (Mpa) in the alveolar bone on axial loading of the tooth-supported fixed partial denture. 
Table 4 The Von Mises stresses (Mpa) in the alveolar bone on buccolingual loading of the tooth-supported FPD

\begin{tabular}{|l|l|l|l|l|}
\hline \multicolumn{2}{|c|}{ Prosthesis material } & $\begin{array}{l}\mathrm{Ni}-\mathrm{Cr} \\
\text { alloy }\end{array}$ & $\begin{array}{l}\text { Porcelain } \\
\text { fused to } \\
\text { metal }\end{array}$ & Zirconia \\
\hline $\begin{array}{l}\text { Von Mises } \\
\text { stress }\end{array}$ & Second premolar & 2.48 & 2.41 & 1.80 \\
\cline { 2 - 5 } & Second molar & 4.96 & 4.49 & 4.30 \\
\hline
\end{tabular}

Abbreviation: FPD, fixed partial denture.

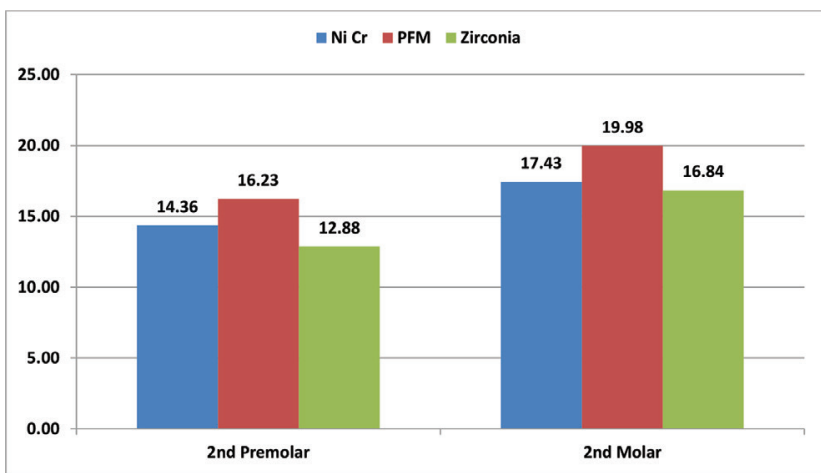

Fig. 14 The Von Mises stresses (Mpa) in the alveolar bone on buccolingual loading of the tooth-supported fixed partial denture.

Table 5 The Von Mises stresses (Mpa) in the alveolar bone on axial loading of tooth implant-supported FPD

\begin{tabular}{|l|l|l|l|l|}
\hline \multicolumn{2}{|c|}{ Prosthesis material } & $\begin{array}{l}\text { Ni-Cr } \\
\text { alloy }\end{array}$ & $\begin{array}{l}\text { Porcelain } \\
\text { fused to } \\
\text { metal }\end{array}$ & Zirconia \\
\hline $\begin{array}{l}\text { Von } \\
\text { Mises } \\
\text { stress }\end{array}$ & \begin{tabular}{l} 
Second premolar \\
\cline { 2 - 5 } \\
molar region
\end{tabular} & 14.36 & 16.23 & 12.88 \\
\hline
\end{tabular}

Abbreviation: FPD, fixed partial denture.

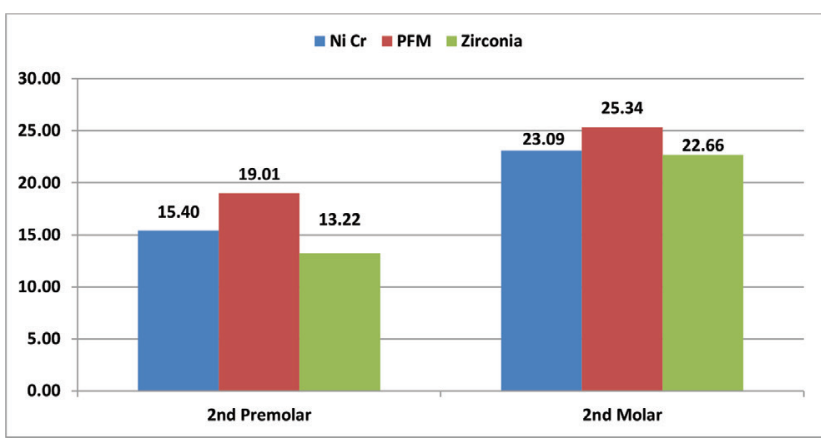

Fig. 15 The Von Mises stresses (Mpa) in the alveolar bone on axial loading of tooth implant-supported fixed partial denture.

In the implant-supported unit, on axial loading, the stress distribution pattern for implant-supported FPDs was nearly identical regardless of the type of prosthesis material used. It was observed that the Von Mises stresses were higher in case of the $\mathrm{Ni}-\mathrm{Cr}$ model, that is, $5.41 \mathrm{MPa}$ in the second premolar
Table 6 The Von Mises stresses (Mpa) in the alveolar bone on buccolingual loading of tooth implant-supported FPD

\begin{tabular}{|l|l|l|l|l|}
\hline \multicolumn{2}{|c|}{ Prosthesis material } & $\begin{array}{l}\text { Ni-Cr } \\
\text { alloy }\end{array}$ & $\begin{array}{l}\text { Porcelain } \\
\text { fused to } \\
\text { metal }\end{array}$ & Zirconia \\
\hline $\begin{array}{l}\text { Von } \\
\text { Mises } \\
\text { stress }\end{array}$ & \begin{tabular}{l} 
Second premolar \\
\cline { 2 - 5 } \\
molar region
\end{tabular} & 15.40 & 19.01 & 13.22 \\
\hline
\end{tabular}

Abbreviation: FPD, fixed partial denture.

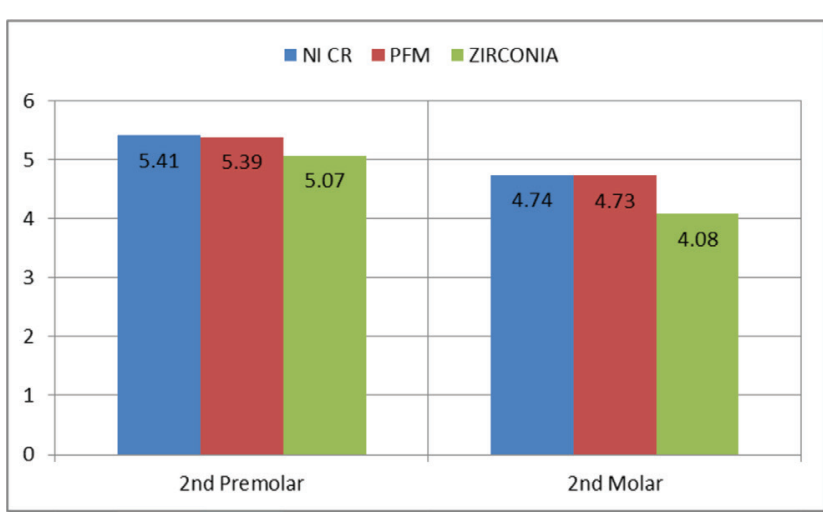

Fig. 16 The Von Mises stresses (Mpa) in the alveolar bone on buc colingual loading of tooth implant-supported fixed partial denture.

Table 7 The Von Mises stresses (Mpa) in the alveolar bone on axial loading of the implant-supported FPD

\begin{tabular}{|l|l|l|l|l|}
\hline \multicolumn{2}{|c|}{ Prosthesis material } & $\begin{array}{l}\mathrm{Ni}-\mathrm{Cr} \\
\text { alloy }\end{array}$ & $\begin{array}{l}\text { Porcelain } \\
\text { fused to } \\
\text { metal }\end{array}$ & Zirconia \\
\hline $\begin{array}{l}\text { Von } \\
\text { Mises } \\
\text { stress }\end{array}$ & $\begin{array}{l}\text { Implant in second } \\
\text { premolar region }\end{array}$ & 5.41 & 5.39 & 5.07 \\
\cline { 2 - 5 } & $\begin{array}{l}\text { Implant in second } \\
\text { molar region }\end{array}$ & 4.74 & 4.39 & 4.40 \\
\hline
\end{tabular}

Abbreviation: FPD, fixed partial denture.

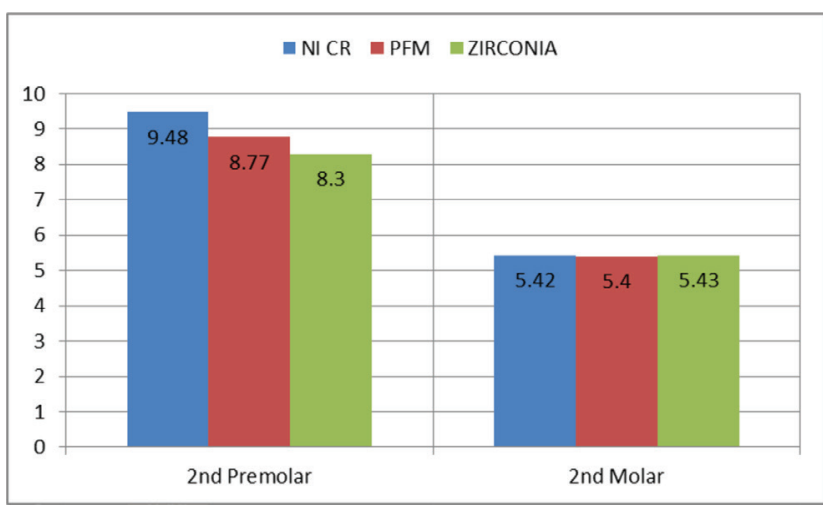

Fig. 17 The Von Mises stresses (Mpa) in the alveolar bone on axial loading of the implant-supported fixed partial denture.

region and $4.74 \mathrm{MPa}$ in the second molar region and were least for all-ceramic, that is, $5.07 \mathrm{MPa}$ in the second premolar region and $4.40 \mathrm{MPa}$ in the second molar region, as shown in -Table 7 and - Fig. 17. 
Table 8 The Von Mises stresses (Mpa) in the alveolar bone on buccolingual loading of the implant-supported FPD

\begin{tabular}{|l|l|l|l|l|}
\hline \multicolumn{2}{|c|}{ Prosthesis material } & $\begin{array}{l}\mathrm{Ni}-\mathrm{Cr} \\
\text { alloy }\end{array}$ & $\begin{array}{l}\text { Porcelain } \\
\text { fused to } \\
\text { metal }\end{array}$ & Zirconia \\
\hline $\begin{array}{l}\text { Von } \\
\text { Mises } \\
\text { stress }\end{array}$ & $\begin{array}{l}\text { Implant in second } \\
\text { premolar region }\end{array}$ & 9.48 & 8.77 & 8.13 \\
\cline { 2 - 5 } & $\begin{array}{l}\text { Implant in second } \\
\text { molar region }\end{array}$ & 5.42 & 5.40 & 5.43 \\
\hline
\end{tabular}

Abbreviation: FPD, fixed partial denture.

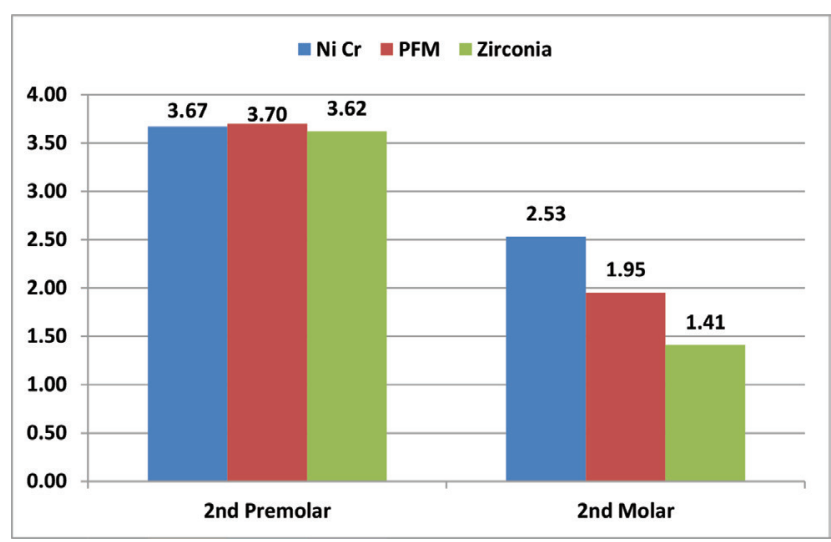

Fig. 18 The Von Mises stresses (Mpa) in the alveolar bone on buccolingual loading of implant-supported fixed partial denture.

On buccolingual loading, it was observed that the Von Mises stresses were much higher in case of the $\mathrm{Ni}-\mathrm{Cr}$ model, that is, 9.48 MPa in the second premolar region and $5.42 \mathrm{MPa}$ in the second molar region and were least for all-ceramic, that is, $8.13 \mathrm{MPa}$ in the second premolar region and $5.43 \mathrm{MPa}$ in the second molar region, as shown in - Table 8 and-Fig. 18.

\section{Discussion}

The long-term success of the implant depends on the maintenance of osseointegration and marginal bone height. Marginal bone height depends on proper distribution of occlusal loads and on adequate function and health of periodontal tissues.

A comparative observation of the stress patterns developed on axial and buccolingual loading of three basic types of FPDs makes it clear that in partially edentulous cases, especially the distal extension ones, the decision to place a tooth implant-supported prosthesis should not be the first choice, except in case where one more implant cannot be placed, or if there is some financial constraint. If at all this is advised, factors like patient's clenching habit or bruxism, which influences the occlusal loading, must be kept in mind, and the bridge span should be kept as short as possible. Implantsupported prostheses are apparently better suited for such cases as the stress distribution appears comparatively much favorable. ${ }^{8,9}$

Pattern of stress distribution for tooth-supported FPD, tooth implant-supported FPD and implant-supported FPD was not affected by the type of prosthesis material we used.

In tooth-supported FPD, the lowest Von Mises stress was seen in the zirconia model, that is, $3.62 \mathrm{MPa}$ in the second premolar region and $1.41 \mathrm{MPa}$ in the second molar region, whereas the $\mathrm{Ni}-\mathrm{Cr}$ model showed the highest Von Mises stress, that is, 3.67 $\mathrm{MPa}$ in second the premolar region and 2.53 MPa in the second molar region on axial loading. The lowest Von Mises stress was seen in the zirconia model, that is, $1.80 \mathrm{MPa}$ in the second premolar region and 4.30 $\mathrm{MPa}$ in the second molar region, whereas the $\mathrm{Ni}-\mathrm{Cr}$ model showed the highest Von Mises stress, that is, 2.48 $\mathrm{MPa}$ in the second premolar region and $4.96 \mathrm{MPa}$ in the second molar region on buccolingual loading.

There was marked differences in stresses observed around the tooth and implant irrespective of the prosthesis material in case of tooth implant-supported FPDs, corroborating the findings of earlier studies. ${ }^{10-13}$ It may be the fact that under axial load tooth tends to depress in alveolus, so more stresses around implant. ${ }^{14}$

In tooth implant-supported prosthesis, Von Mises stresses were much higher in case of the porcelain fused to metal model, that is, $16.23 \mathrm{MPa}$ in the second premolar region and 19.98 MPa in the second molar region and were least for zirconia, that is, $12.88 \mathrm{MPa}$ in the second premolar region and 16.84 MPa in the second molar region on axial loading. The Von Mises stresses were higher in case of the porcelain fused to metal model, that is, $19.01 \mathrm{MPa}$ in the second premolar region and 25.34 $\mathrm{MPa}$ in the second molar region and were least for zirconia, that is, $13.22 \mathrm{MPa}$ in the second premolar region and 22.66 MPa in the second molar region on buccolingual loading.

In implant-supported prosthesis, the Von Mises stresses were much higher in case of the $\mathrm{Ni}-\mathrm{Cr}$ model, that is, 5.41 MPa in the second premolar region and 4.74 MPa in the second molar region and were least for all-ceramic, that is, 5.07 MPa in the second premolar region and 4.40 MPa in the second molar region on axial loading. On buccolingual loading, it was observed that the Von Mises stresses were higher in case of the $\mathrm{Ni}-\mathrm{Cr}$ model, that is, 9.48 MPa in the second premolar region and $5.42 \mathrm{MPa}$ in the second molar region and were least for all-ceramic, that is, $8.13 \mathrm{MPa}$ in the second premolar region and $5.43 \mathrm{MPa}$ in the second molar region.

As we know that a finite element analysis study has got many limitations, instead of comparing the absolute values of stresses and occlusal load, it is more reasonable to interpret them in qualitative terms. Higher or lower load values only change the magnitude of stresses but not the distribution pattern. However, if the load configuration is changed, the stress distribution also changes. Keeping the shortcomings inherent in finite element analysis method in mind, the numerical results of the analysis should be considered as an approximation and evaluated qualitatively, not quantitatively. However, the fact that this method has got limitations should not belittle its importance. It must be understood that the finite element method not only gives us a fair idea of stress distribution pattern under different loading conditions, and thus highlighting the vulnerable 
areas, but also has the potential to guide the designing of restorations, which will lead to a more favorable stress distribution. The findings of this study need to be correlated with those of further clinical studies in order to lend it more authenticity.

\section{Limitation of the Study}

Under this head, further clinical studies are needed to more intensively evaluate the potential of such restoration for the success of prosthodontics rehabilitation of distal extension arches.

\section{Conclusion}

Based on the observations of the present study, it is concluded that for distal extension partially edentulous arches, the choice of rehabilitation is implant-supported FPD which cause more favorable stress distribution.

\section{Conflict of Interest}

None declared.

\section{References}

1 Misch, CE (ed). Contemporary Implant Dentistry. 2nd ed. Marryland, Missouri: Mosby Inc; 2005

2 Wyatt CC, Zarb GA. Treatment outcomes of patients with implant-supported fixed partial prostheses. Int J Oral Maxillofac Implants 1998;13(2):204-211

3 Pratheep KV, Abraham A, Annapoorni H, Vigneshwaran S. Comparative evaluation of stresses in tooth implant connected fixed partial denture by varying the implant design and position: a 3D finite element study. Indian J Dent Res 2013;24(4): 439-445
4 Misch, CE, Contemporary Implant Dentistry. 2nd ed. Missouri: Mosby Inc; 2005

5 Chandrupatta, TR, Introduction to Finite Elements in Engineering. 3rd ed. New Jersey: Prentice Hall Inc; 2002

6 Knoell AC. A mathematical model of an in vitro human mandible. J Biomech 1977;10(3):159-166

7 Tripathi.R. Application of finite element analysis in dentistry. 3rd ed. Pennsylvania, New Jersey;2002:21-53

8 Stegaroiu R, Sato T, Kusakari H, Miyakawa O. Influence of restoration type on stress distribution in bone around implants: a three-dimensional finite element analysis. Int J Oral Maxillofac Implants 1998;13(1):82-90

9 Geng JP, Tan KB, Liu GR. Application of finite element analysis in implant dentistry: a review of the literature. J Prosthet Dent 2001;85(6):585-598

10 Misch CM, Ismail YH. Finite element stress analysis of toothto-implant fixed partial denture designs. J Prosthodont 1993;2(2):83-92

11 Cruz M, Wassall T, Toledo EM. da Silva Barra LP, Cruz S. Finite element stress analysis of dental prostheses supported by straight and angled implants. Int J Oral Maxillofac Implants 2009;24(3):391-403

12 Naveau A, Pierrisnard L. Mechanical effects of implant-tooth rigid connection by a fixed partial denture: a $3 \mathrm{~d}$ finite element analysis. Eur J Prosthodont Restor Dent 2009;17(3):98-104

13 Lin CL, Wang JC, Chang SH, Chen ST. Evaluation of stress induced by implant type, number of splinted teeth, and variations in periodontal support in tooth-implant-supported fixed partial dentures: a non-linear finite element analysis. J Periodontol 2010;81(1):121-130

14 Menicucci G, Mossolov A, Mozzati M, Lorenzetti M, Preti G. Tooth-implant connection: some biomechanical aspects based on finite element analyses. Clin Oral Implants Res 2002;13(3):334-341 